Available online at http://jurnal.stmikroyal.ac.id/index.php/jurteksi

\title{
PENENTUAN JENIS KELINCI PEDAGING TERBAIK DENGAN MENGGUNAKAN METODE FUZZY MULTI CRITERIA DECISION MAKING
}

\author{
Adi Prijuna Lubis \\ Program Studi Sistem Komputer, STMIK Royal \\ email:pri7n4@yahoo.com
}

\begin{abstract}
This decision support system is an alternative to helping rabbit breeders to determine which broiler rabbit is feasible to develop. Along with the increasing public demand for rabbit production. Rabbit breeders are eager to choose the type of rabbit that really qualified and can grow fast. For that decision support system is helping the farmers to choose the type of quality broiler rabbit or feasible to be developed. To facilitate rabbit breeders in developing rabbit prodution in determining the best types of broiler rabbit and To get more accurate results in the process of determining the types of broiler rabbits. Also Applying Decision Support System with Fuzzy Multi Criteria Decision Making method can simplify and accelerate to determine the best types of broiler rabbit to be developed
\end{abstract}

Keywords: broiler rabbit, fuzzy multi criteria decision making

\begin{abstract}
Abstrak: Sistem Pendukung keputusan ini merupakan alternatif untuk membantu peternak kelinci untuk menentukan kelinci pedaging yang layak untuk di kembangkan. Seiring dengan meningkatnya permintaan masyarakat akan produksi kelinci. Peternak kelinci berkeinginan untuk memilih jenis kelinci yang benar benar berkualitas dan dapat berkembang cepat. Untuk itu sistem pendukung keputusan ini membantu pihak peternak untuk memilih jenis kelinci pedaging yang berkualitas atau layak untuk di kembangkan. Untuk memudahkan pihak peternak kelinci dalam mengembangkan produsi kelinci dalam menentukan jenis kelinci pedaging terbaik dan Untuk mendapatkan hasil yang lebih akurat dalam proses penentuan jenis kelinci pedaging. Juga Menerapkan Sistem pendukung keputusan dengan metode Fuzzy Multi Criteria Decision Making dapat mempermudah dan mempercepat untuk menentukan jenis kelinci pedaging terbaik untuk dikembangkan.
\end{abstract}

Kata kunci: kelinci pedaging, fuzzy multi criteria decision making

\section{PENDAHULUAN}

Produksi ternak kelinci memiliki potensi yang sangat besar saat ini. Seiring meningkatnya permintaan masyarakat akan produksi kelinci.
Peternak kelinci semangkin terus berusaha dalam meningkatkan kapasitas produksi ternak mereka. Banyaknya permintaan pasar kepada ternak kelinci baik dari produksi kelinci hias atau kelinci pedaging. Peternak kelinci memilih jenis kelinci yang terbaik untuk 
Available online at http://jurnal.stmikroyal.ac.id/index.php/jurteksi

dikembangkan. Adapun menurut Yurmiati (2003) lima potensi yang bisa dihasilkan dari seekor kelinci, yakni makanan(food), kulit bulu (fur), binatang hias (fancy), pupuk (fertilizer), dan penelitian (laboratory).

Peternak kelinci cendrung mengembangkan jenis kelinci pedaging yang saat ini dibutuhkan untuk pangan, Sebagai penganti daging sapi yang semangkin mahal. Di desa Tinggi Raja ada banyak peternak kelinci pedaging yang belum bisa menentukan kelinci apa yang harus diternakkan lebih baik dan cepat berkembang serta dibutuhkan produksi dengan danging yang maksimal sesuai kebutuhan yang dibutuhkan. Dan peternak itu sendiri berkeinginan untuk meningkatkan ekonomi rumah tangga yang mapan. adapun kelinci yang saat ini di ternakan masih belum maksimal berhubung kebingungan peternak untuk menernakkan jenis kelinci pedaging yang benar benar berkualaitas dan berproduksi cepat dalam berkembang. baik dalam jumlah anakan yang banyak dan juga daging yang berkualitas. Jadi peternak itu sendiri berkeinginan untuk mengembangkan ternaknya, peternak harus memilih jenis kelinci pedaging yang tebaik untuk di ternakan

Dengan adanya sistem pendukung keputusan (SPK) dapat memberikan alternatif solusi bila seseorang atau sekelompok orang sulit dalam menentukan keputusan yang tepat dan sesuai, dengan SPK diharapkan dapat memberikan informasi yang nantinya akan memberikan alternatif solusi pada masalah yang terjadi.

Dengan adanya sistem pendukung keputusan peternak kelinci mampu menentukan dengan cepat dan tepat untuk memilih jenis kelinci pedaging yang layak atau terbaik untuk dikembangkan dikalangan peternak kelinci. Peternak juga mampu memberikan keputusan secara lebih objektif.
Sistem Pendukung Keputusan (Decision Support System). Terdapat banyak metode yang dapat digunakan oleh pengambil keputusan untuk membantu menemukan solusi atau alternatif yang optimum untuk sebuah masalah. Salah satu metode tersebut adalah Fuzzy Multi-Criteria Decision Making.

Fuzzy Multi Criteria Decision Making (FMCDM) adalah suatu Metode pengambilan Keputusan untuk menetapkan alternatif terbaik dari sejumlah alternatif berdasarkan kriteria tertentu. Kriteria biasanya berupa ukuran-ukuran, aturan-atuaran atau standar yang digunakan dalam pengambilan keputusan, menurut Puspitorini dan Afriska 2011. Dengan adanya metode Fuzzy Multi Criteria Decision Making peternak kelinci lebih muda menentukan jenis kelinci pedaging terbaik. Berdasarkan uraian permasalahan di atas maka penulis mengambil judul "Sistem Pendukung Keputusan Untuk Mengetahui Jenis Kelinci pedaging Terbaik Dengan Menggunakan Metode Fuzzy Multi Criteria Decision Making “.

\section{METODOLOGI}

Mengidentifikasi dan menganalisis masalah Analisis masalah pada penelitian ini dilakukan dengan Metode survei yang dilakukan dengan mengunjungi beberapa peternak kelinci. Adapun metode pengumpulan data yang dilakukan oleh peneliti adalah sebagai berikut:

a. Observasi

Melakukan pengumpulan data melalui pendekatan ke lapangan dengan mengambil data-data yang ada di lapangan.

b. wawancara (Interview),

Penulis melakukan wawancara (take and give) kepada masing masing peternak kelinci untuk memperoleh 
Available online at http://jurnal.stmikroyal.ac.id/index.php/jurteksi

keterangan-keterangan yang lebih
komplit.

c. Dokumen

Peneliti mengumpulkan berupa dokumen-dokumen yang diperlukan dari tempat-tempat riset terkait yang digunakan untuk keperluan penelitian.

d. Kuesioner

Peneliti memberikan kuesiner kepada para peternak kelinci.

\section{HASIL DAN PEMBAHASAN}

Analisis Konsep Fuzzy Multi Criteria Decision Making

Dalam proses pemilihan jenis kelinci pedaging terbaik. yang dilakukan dengan menggunakan Fuzzy Multi Criteria Decision Making, diperlukan kriteria-kriteria, bobot kepentingan setiap kriteria dan rating kecocokan alternatif terhadap kriteria untuk melakukan perhitungan sehingga akan didapatkan alternatif terbaik. Dalam hal ini alternatif terbaik dimaksud adalah jenis kelinci pedaging terbaik. Adapun alternatifnya.
Tabel 1. Alternatif

\begin{tabular}{cl}
\hline Alternatif & Keterangan \\
\hline$A_{1}$ & FG (Flemish Giant) \\
$A_{2}$ & NZW (New Zealand White) \\
$A_{3}$ & Lokal \\
$A_{4}$ & Rex \\
\hline
\end{tabular}

Sedangkan kriteria-kriteria yang digunakan terlihat dalam tabel 2.

Tabel 2. Kriteria

\begin{tabular}{cl}
\hline Kriteria & Keterangan \\
\hline$C_{1}$ & Bentuk Badan \\
$C_{2}$ & Kepala \\
$C_{3}$ & Telinga \\
$C_{4}$ & Mata \\
$C_{5}$ & Kaki/Tungkai \\
$C_{6}$ & Ekor \\
$C_{7}$ & Bulu \\
\hline
\end{tabular}

Struktur hirarki masalah dapat dilihat pada gambar 2 .

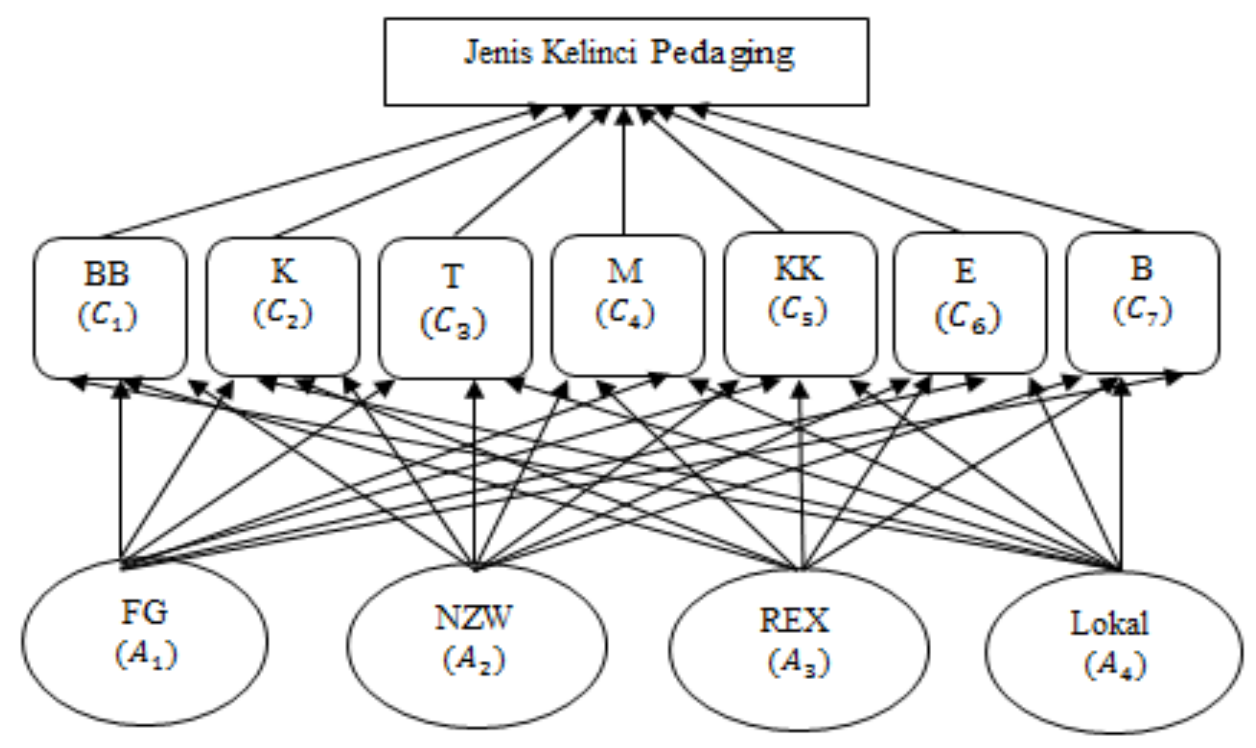

Gambar 2. Struktur Hirarki Masalah 
Available online at http://jurnal.stmikroyal.ac.id/index.php/jurteksi

Untuk menentukan derajat kepentigan masing-masing alternatif terhadap kriteria, fungsi keanggotaan bilangan fuzzy yang digunakan adalah fungsi bilangan fuzzy segitiga, yang fungsi keanggotaannya telah dikemukakan pada persamaan yaitu:

$$
\mu A[x]= \begin{cases}0 \quad ; x<\text { a atau } x>c \\ (x-a) /(b-a) ; & a \leq x \leq b \\ (x-c) /(b-c) ; & b \leq x \leq c\end{cases}
$$

\section{Gambar 3 memperlihatkan grafik/fungsi keanggotaan bobot kepentingan kriteria (W) dengan menggunakan himpunan fuzzy segitiga,}

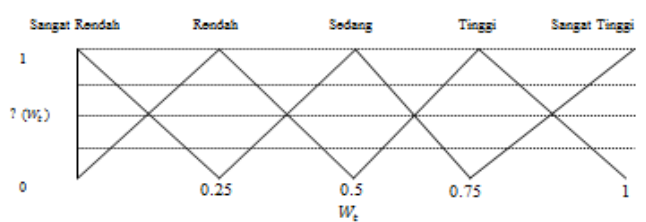

Gambar 3. Fungsi Keanggotaan Untuk Bobot Setiap Kriteria Dengan Himpunan Bilangan Fuzzy Segitiga

$\begin{array}{lrr}\text { Variabel-variabel } & \text { linguistik } \\ \text { yang merepresentasikan } & \text { bobot } \\ \text { kepentingan untuk setiap } & \text { kriteria }\end{array}$ adalah: $\mathrm{T}$ (Kepentingan) $\mathrm{W}=\{\mathrm{SR}, \mathrm{R}, \mathrm{C}$, $\mathrm{T}, \quad \mathrm{ST}\}$ yang masing-masing direpresentaskan dengan bilanganbilangan fuzzy segitiga sebagai berikut:

$$
\begin{aligned}
& \mathrm{SR}=(0,0,0.25) \\
& \mathrm{R}=(0,0.25,0.5) \\
& \mathrm{C}=(0.25,0.5,0.75) \\
& \mathrm{T}=(0.5,0.75,1) \\
& \mathrm{ST}=(0.75,1,1)
\end{aligned}
$$

Untuk memperlihatkan grafik fungsi keanggotaan derajat kecocokan alternatif-alternatif dengan kriteria menggunakan himpunan bilangan fuzzy segitiga.

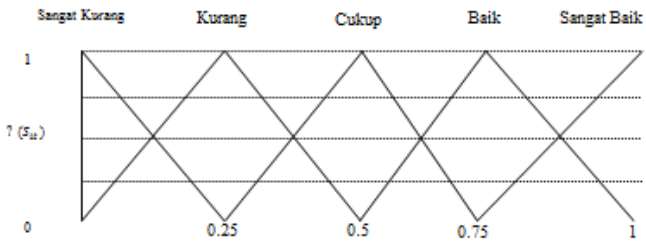

Gambar 4. Fungsi Keanggotaan Untuk Bobot Kecocokan Setiap Alternatif Terhadap Setiap Kriteria Dengan Himpunan Bilangan Fuzzy Segitiga

Derajat kecocokan alternatifalternatif dengan kriteria keputusan adalah: T(kecocokan) $\mathrm{S}=\{\mathrm{SK}, \mathrm{K}, \mathrm{C}, \mathrm{B}$, $\mathrm{SB}\}$, yang masing-masing direpresentasikan dengan bilangan-bilangan fuzzy segitiga sebagai berikut:

$$
\begin{aligned}
& \mathrm{SK}=(0,0,0.25) \\
& \mathrm{K}=(0,0.25,0.5) \\
& \mathrm{C}=(0.25,0.5,0.75) \\
& \mathrm{B}=(0.5,0.75,1) \\
& \mathrm{SB}=(0.75,1,1)
\end{aligned}
$$

Tabel 3. Ranting Kepentingan Untuk Setiap Criteria

\begin{tabular}{lccccccc}
\hline \multicolumn{7}{c}{ Rarting Kepentingan } \\
\hline Kriteria & $C_{1}$ & $C_{2}$ & $C_{3}$ & $C_{4}$ & $C_{5}$ & $C_{6}$ & $C_{7}$ \\
\hline Rarting & ST & ST & $C$ & $\mathrm{C}$ & $\mathrm{T}$ & $\mathrm{C}$ & $\mathrm{C}$ \\
\hline
\end{tabular}

Pada tabel 3 untuk krite-ria yaitu $C_{1}$ (Bentuk Badan), $C_{2}$ (Kepala), $C_{3}$ (Telinga), $C_{4}$ (Mata), $C_{5}$ (Kaki/tungkai), $C_{6}$ (Ekor), $C_{7}$ (Bulu). Di mana bobot kepentingan kriteria, terdapat tiga kriteria yaitu $C_{3}, C_{6}$, ,dan $C_{7}$ yang memiliki bobot kepentingan Cukup (C), dan dua kriteria yaitu, $C_{4}$, dan $C_{5}$, yang memiliki bobot kepen-tingan Tinggi ( $\mathrm{T}$ ), dan dua criteria yaitu, $C_{1}$ dan $C_{2}$ memiliki bobot kepentingan Sangat tinggi (ST). 
Available online at http://jurnal.stmikroyal.ac.id/index.php/jurteksi

Tabel 4. Rating Kecocokan Setiap Alternatif Terhadap Setiap Kriteria

\begin{tabular}{|c|c|c|c|c|c|c|c|}
\hline \multirow{2}{*}{ Alternatif } & \multicolumn{7}{|c|}{ Ranfing kecocokan } \\
\hline & $C_{1}$ & $c_{2}$ & $C_{3}$ & $C_{4}$ & $C_{3}$ & $C_{6}$ & $C_{7}$ \\
\hline$A_{1}$ & SB & B & C & $B$ & B & $\mathrm{C}$ & C \\
\hline$A_{2}$ & $S B$ & SB & C & $B$ & B & C & B \\
\hline$A_{3}$ & B & $c$ & C & $C$ & $B$ & C & C \\
\hline$A_{4}$ & $S B$ & B & C & B & C & C & B \\
\hline
\end{tabular}

Dengan mensubstitusikan bilangan fuzzy segitiga ke setiap variabel linguistik ke dalam persaman diperoleh nilai kecocokan fuzzy pada tabel 5.

Tabel 5. Ranting Kepentingan dan Ranting Kecocokan Setiap Kriteria Untuk Alternatif $A_{1}$

\begin{tabular}{|c|c|c|c|c|c|c|c|c|}
\hline$t=0$ & Kriteria & $c_{1}$ & $c_{2}$ & $\overline{C_{3}}$ & $C_{4}$ & $C_{5}$ & $c_{i}$ & $c_{7}$ \\
\hline \multirow{2}{*}{$A_{1}$} & Ranting bepentingan & ST & ST & $\mathrm{C}$ & $\mathrm{I}$ & I & C & $C$ \\
\hline & Ranting keoccoksm & $S B$ & B & C & B & $B$ & C & $C$ \\
\hline
\end{tabular}

Pada tabel 5 untuk keriteria yaitu $C_{1}$ (Bentuk Badan), $C_{2}$ (Kepala), $C_{3} \quad$ (Telinga), $\quad C_{4}$ (Mata), $C_{5}$ (Kaki/tungkai), $C_{6}$ (Ekor), $C_{7}$ (Bulu). Ranting kepentingan $\mathrm{C}$ (Cukup), $\mathrm{T}$ (Tinggi), ST (Sangat Tinggi). Ranting Kecocokan C (Cukup), B (Baik), SB (Baik). Di mana untuk mencari nilai index kecocokan untuk setiap alternatif $Y_{1}, Q_{1}$, dan $Z_{1}$, untuk masing-masing ranting nilai diambil dari fuzzy segitiga.

Pada alternatif $A_{1}$ untuk mencari index kecocokan untuk setiap alternatif $Y_{1}, Q_{1}$, dan $Z_{1}$ diambil dari Tabel. Rating Kecocokan Setiap Alternatif Terhadap Setiap Kriteria, dan diambil setiap alternatif pada tabel. Ranting Kepentingan dan Ranting Kecocokan Setiap Kriteria Untuk Alternatif $A_{1}$. Dari hasil perhitungan, terlihat bahwa pada alternatif $A_{1}, \mathrm{FG}$ (Flemish Giant) memiliki indeks kecocokan fuzzy: $Y_{1}=0.23214286, Q_{1}$ $=0.51785714, Z_{1}=0.81250000$.
Di mana pada alternatif $A_{2}$ untuk mencari index kecocokan untuk setiap alternatif $Y_{2}, Q_{2}$, dan $Z_{2}$ diambil dari Tabel Rating Kecocokan Setiap Alternatif Terhadap Setiap Kriteria,. Dari hasil perhitungan, terlihat bahwa pada alternatif $A_{2}$, NZW (New Zealand White) memiliki indeks kecocokan fuzzy: $Y_{2}=0.26785714, \quad Q_{2}=$ $0.57142857, Z_{2}=0.873928571$.

Pada alternatif $A_{3}$ untuk mencari index kecocokan untuk setiap alternatif $Y_{3}, Q_{3}$, dan $Z_{3}$ diambil dari Tabel. Rating Kecocokan Setiap Alternatif Terhadap Setiap Kriteria,. Dari hasil perhitungan, terlihat bahwa pada alternatif $A_{3}$, Lokal memiliki indeks kecocokan fuzzy: $Y_{1}=$ $0.16071429, \quad Q_{1}=0.41964286, Z_{1}=$ 0.74107143 .

Di mana pada alternatif $A_{4}$ untuk mencari index kecocokan untuk setiap alternatif $Y_{4}, Q_{4}$, dan $Z_{4}$ diambil dari Tabel Rating Kecocokan Setiap Alternatif Terhadap Setiap Kriteria,. Dari hasil perhitungan, terlihat bahwa pada alternatif $A_{4}$, REX memiliki indeks kecocokan fuzzy: $Y_{4}=$ $0.22321429, \quad Q_{4}=0.50892857, Z_{4}=$ 0.80357143 .

Tabel 6. Index Kecocokan Untuk Setiap Alternatif

\begin{tabular}{clll}
\hline \multirow{2}{*}{ Altenatif } & \multicolumn{3}{l}{ Index Kecocokan Pway } \\
\cline { 2 - 4 } & $Y$ & $Q$ & $Z$ \\
\hline$A_{1}$ & 0.23214285 & 0.51785714 & 0.81250000 \\
$A_{2}$ & 0.26785714 & 0.57142857 & 0.839285771 \\
$A_{3}$ & 0.16071429 & 0.41964285 & 0.74017143 \\
$A_{4}$ & 0.22321429 & 0.50892857 & 0.80357143 \\
\hline
\end{tabular}

Dengan mendistribusikan indeks kecocokan fuzzy dengan mengambil derajat keoptimisan $(\alpha)=0$ (tidak optimis), $\alpha=0.5$ dan $\alpha=1$ (sangat optimis), maka akan diperoleh nilai integral untuk setiap alternatif.

Perhitungan untuk nilai $(\alpha)=0$ 
Available online at http://jurnal.stmikroyal.ac.id/index.php/jurteksi

dimbil dari Tabel Index Kecocokan

Untuk Setiap Alternatif:

$\mathrm{I}_{1}^{-0}=\left(\frac{1}{2}\right) *((0) *(0.81250000)+(0.51785714)+(1-0) *(0.23214286))=0,375$

$\mathrm{I}_{1}^{\frac{0}{1}}=\left(\frac{1}{2}\right) *((0) *(0.839288571)+(0.57142857)+(1-0) *(0.26785714))=0,41964286$

$\mathrm{I}_{1}^{-}=\left(\frac{1}{2}\right) *((0) *(0.74107143)+(0.41964286)+(1-0) *(0.16071429))=0,290178575$

$\mathrm{I}_{1}^{-\frac{0}{1}}=\left(\frac{1}{2}\right) *((0) *(0.80357143)+(0.50892857)+(1-0) *(0.22321429))=0,36607143$

Perhitungan untuk nilai $(\alpha)=0.5$

$\mathrm{I}_{1}^{-\frac{1}{1}}=\left(\frac{1}{2}\right) *((0.5) *(0.81250000)+(0.51785714)+(1-0.5) *(0.23214286))=0,520089285$

$\mathrm{I}_{1}^{-0}=\left(\frac{1}{2}\right) *((0.5) *(0.839288571)+(0.57142857)+(1-0.5) *(0.26785714))=0,56250071$

$\mathrm{I}_{1}^{-\frac{0}{1}}=\left(\frac{1}{2}\right) *((0.5) *(0.74107143)+(0.41964286)+(1-0.5) *(0.16071429))=0,43526786$

$\mathrm{I}_{1}^{-0}=\left(\frac{1}{2}\right) *((0.5) *((0.5) *(0.80357143)+(0.50892857)+(1-0.5) *(0.22321429))=0,51116071$

Perhitungan untuk nilai $(\alpha)=1$

$\mathrm{I}_{1}^{-}=\left(\frac{1}{2}\right) *((1) *(0.81250000)+(0.51785714)+(1-1) *(0.23214286))=0,66517857$

$\mathrm{I}_{1}^{-0}=\left(\frac{1}{2}\right) *((1) *(0.839288571)+(0.57142857)+(1-1) *(0.26785714))=0,70535857$

$\mathrm{I}_{1}^{-0}=\left(\frac{1}{2}\right) *((1) *(0.74107143)+(0.41964286)+(1-1) *(0.16071429))=0,580357145$

$\left.\mathrm{I}_{1}^{-0}=\left(\frac{1}{2}\right) *(0.80357143)+(0.50892857)+(1-1) *(0.22321429)\right)=0.65625$

Tabel 7. Nilai Tototal Integral Setiap Alternatif

\begin{tabular}{|c|c|c|c|}
\hline \multirow{2}{*}{ Aitematif } & \multicolumn{3}{|c|}{ Nilai Total Integral } \\
\hline & $\alpha=0$ & $\alpha=0,5$ & $\alpha=1$ \\
\hline$A_{1}$ & 0.375 & 0.520089285 & 0.66517857 \\
\hline $\mathrm{A}_{2}$ & 0.41964286 & 0.56250071 & 0.70535857 \\
\hline $\mathrm{A}_{3}$ & 0.290178575 & 0.43526786 & 0.580357145 \\
\hline $\mathrm{A}_{4}$ & 0.36607143 & 0.511160715 & 0.65625 \\
\hline
\end{tabular}

Dari table 7 terlihat bahwa $A_{2}$ memiliki total integral terbesar dan derajat keoptimisannya, maka dari itu peternak kelinci bisa memutuskan untuk menentukan jenis kelinci pedanging terbaik yang perlu dikembangkan dilingkungan. Peternak tersebut.

Setelah dilakukan analisis ulang dan pengujian terhadap hasil perhitungan manual dengan mengunakan fuzzy nilai total integra, ternyata hasil perhitungan manual yang diperdapat dipertegas kembali kebenarannya oleh peneliti.

Di mana hasil perhitungan dilakukan di atas, maka alternatif memilih jenis kelinci pedaging terbaik pada kelinci pedaging, yaitu kelinci jenis pedaging NZW (New Zealand White) merupakan alternatif terbaik untuk 
Available online at http://jurnal.stmikroyal.ac.id/index.php/jurteksi

dipilih dan dikembangkan di lingkungan peternak kelinci pedaging.

Tabel 8. Nilai $F$ Integral Perhitungan Urutan Perangkingan

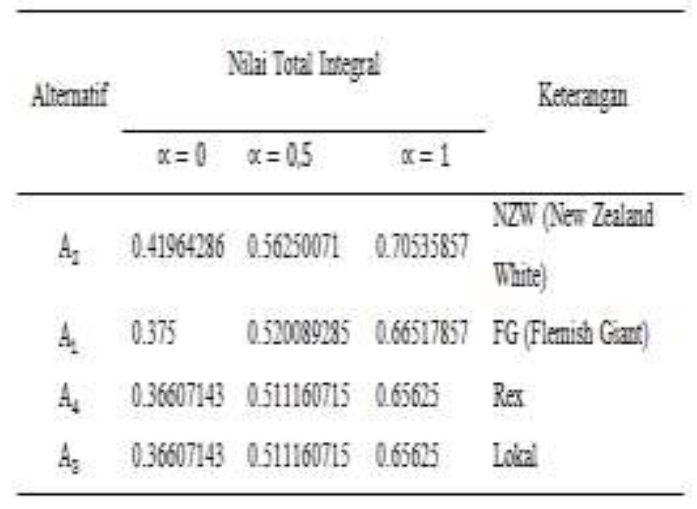

Dari perhitungan perangkingan nilai total integral dari semua alternatif yang ada, terlihat bahwa Alternatif $A_{2}$ NZW (New Zealand White) memiliki nilai yang tertinggi, sehingga dapat disimpulkan bahwa alternatif tersebuat adalah alternatif yang terbaik.

\section{SIMPULAN}

Berdasarkan hasil penelitian dapat disimpulkan sebagai berikut :
1. Penggunaan sistem dengan menggunakan metode FMCDM dapat membantu menentukan alternatif yang baik dalam sebuah sistem pendukung keputusan. Dengan kepuasan tersendiri

2. Metode Fuzzy Multi Criteria decision Making (FMCDM) dapat digunakan untuk menyelesaikan permasalahan yang bersifat multi kriteria dan data ketidak pastian pada penelitian ini yakni Sistem Pendukung Keputusan Penentuan jenis kelinci terbaik khususnya pada kelinci pedaging.

3. Penerapan sistem pendukung keputusan dengan metode Fuzzy Multi Criteria Decision Making dapat membantu mempermudah untuk menentukan sebuah pilihan atau keputusan dalam pemilihan jenis kelinci pedaging yang baik. sistem ini bisa kita terapkan dengan menggunakan tool yang sudah ada, dan Sistem ini hanya sebagai alat bantu bagi pengambil keputusan dalam menentukan jenis kelinci peda-ging terbaik, namun keputusan akhir tetap berada di tangan pengambil keputusan.

\section{DAFTAR PUSTAKA}

Hasugian, P.H. (2012). fuzzy Multiple Attribute Decision Making Untuk Menentukan Tenaga kerja dengan Metode Simple Additive Weighitng (Studi Kasus: PT Cahaya Bintang Medan). Pelita Informatika Budi Darma.

Muktadir, A. \& Purdianto, I. (2013). Sistem Pendukung Keputusan Kenaikan Jabatan Menggunakan Metode Profile Mitching (Studi Kasus di PT. Industri
Kemasan Semen Gersik).

Seminar Nasional Aplikasi

Teknologi Informasi (SNATI)

Yogyakarta, 15 juni 2013

Muslihudin, M. \& Rohma, L. (2014).

Sistem Pendukung Keputusan

Seleksi Siswa Berperestasi Pada

SMK Nurul Huda Pringsewu Menggunakan Metode PHP. Konferensi Nasional Sistem Informasi 2014. STMIK 
Available online at http://jurnal.stmikroyal.ac.id/index.php/jurteksi

Dipanegara Makassar 27 Pebruari1Maret 2014

Analytic Network Process (ANP) Untuk Penempatan Kerja Pada Sebuah Instansi. Jurnal Petir

Yulianto, S., dkk. (2008). Aplikasi Pendukung Keputusan Dengan Menggunakan Logika Fuzzy
Susanti, M.N.I. (2011). Sistem Pendukung Keputusan Dengan (Studi Kasus: Penentuan Spesifikasi Komputer Untuk Suatu Paket Komputer Lengkap). Jurnal Informatika. $4(2)$ 
Available online at http://jurnal.stmikroyal.ac.id/index.php/jurteksi 
Jurnal Pena Edukasi

ISSN 2407-0769

Vol. 4 No. 2, Maret 2017

e-ISSN 2549-4694 